\title{
Non-Neoplastic Esophageal Disorder
}

National Cancer Institute

\section{Source}

National Cancer Institute. Non-Neoplastic Esophageal Disorder. NCI Thesaurus. Code C53497.

A non-neoplastic disorder that affects the esophagus. Representative examples include infections, ulcers, and gastroesophageal reflux disease. 